This item was submitted to Loughborough's Research Repository by the author.

Items in Figshare are protected by copyright, with all rights reserved, unless otherwise indicated.

\title{
Technology-enhanced learning in coaching: a review of literature
}

PLEASE CITE THE PUBLISHED VERSION

https://doi.org/10.1080/00131911.2018.1457010

PUBLISHER

Taylor \& Francis (@ Educational Review)

VERSION

AM (Accepted Manuscript)

PUBLISHER STATEMENT

This is an Accepted Manuscript of an article published by Taylor \& Francis in Educational Review on 23 Apr 2018, available online: https://doi.org/10.1080/00131911.2018.1457010

\section{LICENCE}

CC BY-NC-ND 4.0

\section{REPOSITORY RECORD}

Cushion, Christopher, and Robert C. Townsend. 2019. "Technology-enhanced Learning in Coaching: A Review of Literature". figshare. https://hdl.handle.net/2134/35430. 
1 Technology-enhanced learning in coaching: A review of literature.

2 Christopher J. Cushion ${ }^{\mathrm{a}} \&$ Robert C. Townsend ${ }^{\mathrm{a}}$

3 School of Sport, Exercise and Health Sciences, Loughborough University, UK.

4 Corresponding author: Christopher Cushion, School of Sport, Exercise and Health Sciences,

5 Loughborough University, Loughborough, UK, LE11 3 TU.

$6 \quad$ c.cushion@1boro.ac.uk.

7

8

9

10

11

12

13

14

15

16

17

18

19

20 


\section{Abstract}

22 The purpose of this review was to address the central theme of technology-enhanced learning 23 (TEL) in coaching. Technology-enhanced learning' (TEL), has become a widely-accepted term 24 for describing the interface between digital technology and teaching. The aim was to consider 25 the evidence of TEL in coach education, and where appropriate the wider educational field. 26 The review sought to contribute to an evidence-base of suggestions that can be promoted and 27 developed inside and outside of coach development structures and interventions for TEL. In 28 addition, the review to outline future areas for research, and to stimulate debate about the 29 implementation and effectiveness of technology-enhanced coach learning. The review utilised 30 a critical methodology, using principles of systematic review to gather evidence pertaining to 31 TEL in coaching. From this number and considering the inclusion criteria sixty-four articles 32 were included and reviewed in detail. The review revealed how despite the use of technology 33 in coaching, teaching and learning the evidence of their efficacy is weak, and the use of TEL 34 in coaching requires further longitudinal research that considers learner, pedagogy and 35 pedagogic design in context, in order to understand its potential impact on optimising coach 36 development pedagogies, and therefore, contributing to a discourse of effective coach learning. 
51 Coach learning is fundamental to the development of high quality coaching (Townsend, 52 Cushion \& Smith, 2017; Stodter \& Cushion, 2017). Consequently, research has attempted to understand the process of coach learning (e.g. Wright, Trudel \& Culver, 2007), commonly by attempting to categorise sources of coaches' knowledge (e.g. Erickson et al., 2008; MacDonald et al., 2015) and understand the use of discrete learning practices such as reflection (e.g. Taylor et al., 2015; Gilbert \& Trudel, 2001). The emerging consensus is that coach learning remains an idiosyncratic and often informal process reflective of the complex reality in which coaches work. As a result, in recent years alongside the significant increase in the provision of formal coach education (Gilbert \& Trudel, 1999), academic interest in coach education continues to grow. The substantial body of literature on coach development however demonstrates a widelyheld dissatisfaction with traditional 'face-to-face' coach education opportunities (Stoszkowski \& Collins 2016; Cushion et al., 2010), with 'learning' instead controlled and shaped within coaching sub-cultures by a power-dominated process of socialisation (Cushion, Jones \& Armour, 2003; Piggott, 2011). Indeed, it is well established that informal learning experiences contribute more to the development of coaching knowledge and practice than formal education (e.g. Cushion et al., 2003; Mallett, Trudel, Lyle \& Rynne, 2009; Stoszkowski \& Collins 2016; inter-alia). This is because coach education programmes tend to be standardised, instrumental and often developed in isolation from the "messy reality" of practice (Cushion et al., 2010; Jones, Morgan \& Harris, 2012), with coaches often 'filtering' knowledge from coach education according to "what works" in their own particular contexts (Stodter \& Cushion, 2014, p. 75).

There is, therefore, an ongoing concern to outline optimal frameworks for formal coach development (Williams, Alder \& Bush, 2016; Stoszkowski \& Collins, 2014) that bring coach learning "under greater critical control" (Eraut, 1994, p. 62). An unfortunate consequence of this is a proliferation of 'effective' prescriptions for coach education despite little evidence of the impact of such pedagogies on learning. These have included various 'constructivist' approaches that have included attempts to situate learning through communities of practice (e.g. Stoszkowski \& Collins, 2014a) narrative approaches (e.g. Douglas \& Carless, 2008), ethnodrama (Morgan, Jones, Gilbourne \& Llewellyn, 2013) and problem-based learning (e.g. Jones \& Turner, 2009; Driska \& Gould, 2014). One such perspective that has gained traction within coaching is the increased interest in the use of technologies to facilitate and enhance 
become a widely-accepted term for describing the interface between digital technology and teaching - replacing popular terminology such as 'e-learning', 'learning technology' and 'computer-based learning' (Bayne, 2015, p. 5). Research has suggested that coaches are increasingly open to the use of technology to support their development, which may be due to their preferences for informal, bespoke learning experiences (Trudel, Culver \& Werthner, 2013; Stoszkowski \& Collins 2016). It has been suggested that technology can be a useful and innovative means to support and structure coaches' learning, through the integration of technology in the design of coach education pedagogy (Stoszkowski et al., 2015).

However, research to support technology-enhanced leaning in coaching is still a developing area (Stoszkowski et al., 2015). While research (e.g. Stoszkowski \& Collins, 2016) suggests technology is used both as a source of knowledge and as a resource for coaches who 'self-medicate' their learning needs, the potential for technology to support and enhance coach learning remains critically underexplored. This is particularly important considering the use of technologies in coaching and the wider educational field is outpacing the development of theoretical frameworks and any underlying evidence base supporting their use (Gunawardena et al., 2009; Stoszkowski \& Collins, 2014). It is not yet clear however, how best to support the integration of technology into coach development as a means of facilitating coach learning. Therefore, there is a pressing need for an evidence-base concerning how technology is currently used in coach learning and the impact of its use, as well as developing guidelines about how it might be integrated to improve and 'enhance' coach education and learning. The purpose of this paper is to address the central theme of technology-enhanced learning (TEL) in coaching. The aim is to review the literature concerned with TEL in coach education, and where appropriate the wider education and sport pedagogy fields. The review seeks to contribute to an evidence-base of suggestions that can be promoted and developed inside and outside of coach development structures and interventions for TEL. In addition, the review seeks to identify future areas for research, and to stimulate debate about the implementation and effectiveness of technology-enhanced coach learning. Central to the review is the taken for granted assumption that technology can 'enhance learning', hence questions about how technology enhances learning are important and as well as what value is being added.

\section{Methodology}

\section{Procedure overview}


113 The review utilised a critical methodology that drew upon the principles of a systematic review.

114 Because of the extensive body of literature across the fields of education, technology and 115 learning and the growing body of literature in understanding how coaches learn, the review 116 was divided into a number of stages (cf. Cushion et al., 2010). First, a descriptive map of the 117 field of TEL was assembled. This included the synthesis of a wide range of empirical, 118 conceptual and review studies in order to identify evidence as to 'what works' in applying 119 technology to enhance learning across settings such as higher education, teacher-training and 120 pedagogy. Research relating to the use of TEL in the broader education, pedagogy and 121 technology fields, inclusive of critical reviews of the literature, conceptual dilemmas or issues and the underpinning assumptions of TEL as well as examples of best practice, principles and evidence for TEL were identified. Next, research was identified that investigated different modalities of TEL and its implementation to coaching, coach education and coach learning.

The second phase of the review comprised of analysis and synthesis of the included papers to form a review narrative. The literature was organised according to Kirkwood and Price's (2014) conceptual framework. This framework identifies the following means of categorising research in TEL - operational improvement, quantitative change in learning, and qualitative change in learning (Kirkwood \& Price, 2014). This enabled a structure to the discussions surrounding coach learning and TEL and also provided a framework to consider research from other relevant domains. The framework was a pragmatic conceptual tool to help organise a disparate body of literature.

\section{Inclusion Criteria}

134 The review considered the relevant English language research undertaken between 2010 and 2016 with a particular focus on technology-enhanced learning applied to coaching, coach 136 learning and coach education, while including literature in relevant related disciplines (e.g. 137 education, professional learning, and educational technology). The review considered research that was published in peer-reviewed scholarly journals as well as books/book chapters relevant to the research questions. TEL features prominently in disciplines such as professional learning and education and constitutes a large body of literature, and TEL itself is a broad term

141 encompassing many modalities. For this reason, generating specific evidence regarding the 142 impact of technology on learning, and also connecting coaching to the wider TEL field proved 143 challenging. Whilst it was clear that many researchers were interested in the use of, and benefits 144 for, implementing TEL, there remained very little evidence as to what 'worked' in specific 
145 contexts with varying demographic populations. This process of gathering evidence regarding

146 TEL and its application to coaching was monitored by three measures of quality against which 147 each article was assessed (cf. Cushion et al., 2010). These were:

148

149

150

151

152

- Trustworthiness of results assessed by the quality of the study (methodological rigour).

- Appropriateness of the study for addressing the research question (relevance).

- Appropriateness of focus for answering review question (topic relevance).

\section{Search Strategy}

The initial search strategy involved identifying databases relevant to the research (e.g. psychINFO, SportDiscus; ProQuest), using various combinations of key words (e.g. technology-enhanced learning AND coaching; technology-enhanced AND learning AND coaching OR education OR development). Once identified, an exhaustive search using these databases was conducted. This search was further supplemented by an extensive manual search across relevant journals in the fields of education, learning and technology, as well as that of coaching to identify relevant literature. This was not unproblematic, as despite the substantial body of literature investigating the use of technological resources to enhance learning outcomes across the field of education, coaching research that utilised technology was much more difficult to identify. In order to limit the numbers of relevant articles pertaining to TEL interventions papers that were subject specific were excluded (e.g. language learning; science; computer studies) but articles that were discipline specific were included (e.g. higher education; pedagogy; professional development).

As a result, two-layers of research were investigated, first; research relating to the use of TEL in the broader education, pedagogy and technology fields, inclusive of critical reviews of the literature. Second, research was identified that investigated different modalities of TEL and its implementation to coaching, coach education and coach learning. The initial search strategy involved reading the abstracts of selected papers against the inclusion and exclusion criteria, removing duplicate papers and compiling a database of research notes as to the key points of each paper. All articles without a clear focus on TEL related to the aims of the review were excluded. From the initial searches over 5000 abstracts were reviewed and yielded 262 papers to be read more closely. From this number and considering the inclusion criteria 64 articles were included and reviewed in detail. Ensuring the review was systematic and transparent presented challenges, particularly in identifying robust and defensible 
176 inclusion/exclusion criteria, resulting in a tension between inclusion and research that was 177 useful, relevant, and having an impact on the field. For this reason, judgement of value was 178 based on an aggregation of methodological quality, methodological relevance, and topic 179 relevance (cf. Cushion et al., 2010).

180 Analysis

181 The papers were analysed deductively against Kirkwood and Price's (2014) organising 182 framework. Each article was read several times in order to become familiar with findings about 183 enhancements and the evidence presented to support these claims. Each author read the articles independently and noted salient points relating to (1) the driver for the intervention/study, (2) the enhancement sought, (3) the research/evaluation approach and methods, and (4) the type(s) of evidence acquired. As part of the analysis the role of technology were considered in terms of three outcomes; first, replicating existing 'teaching' practices, second, supplementing existing teaching practices, and lastly transforming teaching or learning processes (cf. 189 Kirkwood \& Price, 2014). Replicating existing practices involved an element of 'conventional' delivery that was copied and delivered using a form of technology. Supplementing practices involved resources or tools being made available to increase flexibility for learners, with the research examining the response to the increased flexibility. Transforming practices involved a structural change in the teaching and learning process using technology (see table one below).

\section{Insert Table 1 here}

195 Furthermore, the literature often identified more than one 'enhancement' for example, 196 increases in peer-to-peer learning and critical thinking - and therefore the research was 197 organised into; operational improvement, quantitative change in learning, and qualitative 198 change in learning (cf. Kirkwood \& Price, 2014). Table 2 below lists and maps the studies conducted in coaching relating to the enhancement identified - the gaps denote no studies conducted in coaching reporting the particular conception of enhancement.

\section{Insert Table 2 here}

202 Table 1 served as a map of the intervention studies according to their use of technology, while 203 table 2 enabled us to map an understanding of how enhancement was conceived. Overall, as 204 can be seen, most papers were concerned with enhancement as qualitative changes in learning, 205 or operational improvement. Only one study sought to demonstrate a quantitative change in 
206 learning, and while two studies reported qualitative changes in learning while using 207 quantitative data collection methods.

\section{Overview}

209 The following overview is organised into three parts. First, the TEL interventions in coaching 210 are mapped and reviewed against an organising framework utilised in the wider educational 211 literature (Kirkwood \& Price, 2014). Next, the wider educational field (including physical 212 education and sport pedagogy) is reviewed to attempt to synthesise and draw out some 213 recommendations for best practices in the use of technology to support and enhance learning. 214 Finally, we discuss methodological, theoretical and practical issues related to research on 215 technology-enhanced learning applied to coaching, offering some recommendations for 216 developing a research agenda.

\section{Qualitative Change in Learning}

218 Kirkwood and Price (2014) suggest that a qualitative change in learning with the use of 219 technology promotes reflection on learning and practice, deeper engagement, and richer 220 understanding. For example, Stoszkowski and Collins (2015) and (2014) analysed the content 221 of twenty-four and twenty-six undergraduate students' online blogs to examine the quality of reflections and the extent that blogging promoted higher-order thinking. In the 2014 study descriptive reflection exceeded higher-order thinking and reflection, though the blogs showed a trajectory toward higher-order thinking. While the blogs provided an effective platform for supporting tutor-student interaction an online community did not emerge. The authors suggest that sporadic use of the blog and a lack of a reflective structure inhibited the process of reflection. Moreover, simply providing access to peers was insufficient to promote peer-topeer engagement and develop a learning 'community'. In the 2015 study the authors used a framework of knowledge typologies to analyse and classify blog entries and found an improvement in higher-order thinking processes and reflection but that these were variable and progressed in a non-linear fashion. The authors did report an increase in peer collaboration and

232 posited the creation of a 'community of practice' as the tutor and supporting structures provided 233 a clear guide. However, in line with research in the wider educational literature (e.g. Hew \& 234 Cheung, 2013), because of the research design the authors were unable to clarify if the improvements were due to the blogs themselves or the way that the collaborative tool was used. 
In a further study, Stoszkowski et al. (2015) sampled twenty-three undergraduate student coaches to take part in four semi-structured focus group interviews gauging their perceptions about the use of group blogging for reflection and learning. Participants reported positively about their experiences and indicated improvements in reflection, knowledge acquisition and their coaching practice. The authors suggested that the formal structure

241 provided by the course and tutor and peer support were key mechanisms in facilitating 242 reflection. Moreover, the format and accessibility of the platform on mobile devices and ability 243 to engage in the work asynchronously was outlined as helping student uptake. These findings were balanced with participants having time and the 'attitude' to engage with the group blog as well as issues with group dynamics and group sizes. The authors pointed out that the technology was enabling of learning rather than being the mechanism for learning itself, a finding echoed in the wider educational field (e.g. Hannafin \& Land, 1997).

Jones and colleagues (2015) examined the use of video diaries to support coach learning and reflection using evidence from a long-term (three year) case study tracking twenty-seven coaching students through their undergraduate coaching course. The authors challenge some of the positive claims surrounding the use of video diaries showing their use produced less engagement with reflection than written logs and group discussion. The perceived burden of completing entries was highlighted as outweighing the perceived benefits of using the approach. As a result, the production of video entries then became mediated by tutor involvement. The authors pointing out that it is important to consider "with whom and in what context will they be used, factoring in issues of time, inclination and general enthusiasm from potential respondents" (p. 407) as well as optional versus compulsory use. Furthermore, Mead, Spencer and Kidman, (2016) interviewed six performance-level coaches in four invasion sports about their perceptions of the use of video self-reflection as a tool for learning within their ongoing development. Contrary to Jones et al. (2015) the authors highlight the positive reception use of video technology to support reflection, but also indicate time and a lack of training/experience as barriers to its use.

Partington et al. (2015) tracked the coaching behaviour of five elite football coaches over three seasons (approximately 30 months) using a computerised observation system (Coach Analysis Intervention System, CAIS) (Cushion, et al., 2012) and video feedback. The study reported significant differences in four behaviours, instruction, feedback, silence and 
268 structure for reflective conversations, improved self-awareness and provided a trigger for 269 behaviour change evidenced over the duration of the research. In a similar vein, Kuklick, 270 Gearity and Thompson (2015) monitored the reflective activity of twenty-one coaching 271 students over a 12-week practicum. The students used an online journal and responded to 272 weekly reflective prompts that were posted by course tutors. Students completed the self273 reflection and insight scale (SRIS; Grant, Franklin \& Langford, 2002) and the quality of 274 reflection was measured using an adopted reflection rubric. Pre- and post-test scores from the

275 SRIS showed a significant improvement in measures considering intrapersonal knowledge and 276 an increase in the levels of reflection from the rubric. The authors also highlighted the use of 277 technology as a means to facilitate better connections between students and tutors.

\section{Quantitative Change in Learning}

279 Kirkwood and Price (2014) suggest that quantitative changes in learning tend to be interpreted 280 as an improvement in the acquisition or retention of knowledge, increased engagement or time281 on-task and students achieving improved test scores or assessment grades. In the only study to 282 take this approach, Glang et al. (2010) designed an online education course for youth sport 283 coaches. The course was designed to develop sport concussion prevention and management 284 practices. The authors developed a short three module online resource that included scenarios. 285 Seventy-five coaches took part in a randomised control trial with pre-and post-test measures. 286 Significant differences were reported between treatment and control participants on measures 287 of: (a) knowledge about sports concussion, management, and prevention; (b) attitudes about 288 the importance of preventing sports concussion; and (c) intention and self-efficacy in sports 289 concussion management and prevention. The authors argued that the results illustrated the 290 course had an impact on understanding - though acknowledge that the study cannot suggest

291 the extent that the coaches would use the skills or knowledge in practice.

\section{Operational Improvement}

293 Operation improvement refers to the potential efficacy of TEL in coach learning and 294 development. For example, Hay et al. (2012) proposed using Web 2.0 technology to develop 295 assessment of coaching practice as learning experiences. Drawing on protocols for online 296 clinical assessment of practical skills in sports medicine, the authors suggested a three-stage 297 model that included tutor exemplars as a reference point for learners, learner-generated video 
298 of practical skills with tutor feedback, and real-time video conferencing summative assessment 299 of practical skills. Despite no evaluative research design, Hay et al. (2012) argued that the 300 technology has the potential to facilitate a shifting of responsibility to the coach in the context 301 of their development. Kuklick et al. (2016), based on feedback from a case study with a single 302 coach, highlighted the potential for technology-based learning community meetings to connect 303 coaches with trustworthy and knowledgeable facilitators and peers in a manner that fits with 304 the coaches' busy schedules - and hence the potential for such technology to promote coach 305 learning effectiveness.

\section{Use of Technologies}

307 Analysis of the limited literature and evidence available on technology in coaching and coach 308 development suggests that technology offers a means of increasing the efficiency of existing coach development processes, enhancing reflective practices or offering a means to transform coach education pedagogy. However, the limited evidence on coaching means that it is difficult to synthesise and draw out best practices or evidence pertaining to different modes of

312 technology to enhance learning. There is a wide range of Web 2.0 technologies available for 313 use in learning, however in coaching, technology is commonly used to replicate or supplement 314 traditional activities through online reflection, social spaces, online collaboration or online 315 delivery (Hew \& Cheung, 2013). In the next section, we consider the literature from education 316 and sport pedagogy in an attempt to synthesise recommendations for the integration of 317 technologies into coaching and coach development. Hew and Cheung (2013) reviewed twenty318 seven articles considering the use of Web 2.0 technology in higher and secondary education 319 they identified podcasts as the most commonly investigated, with investigations also 320 considering, blogs, wikis, social media and virtual (learning) environments (VLE). In the next section, each use is now considered.

\section{Podcast}

323 Evidence from educational research suggests that podcasts with supporting materials have 324 reported generally positive results compared to just 'lectures' or 'traditional delivery (Hew \& 325 Cheung, 2013). The positive results stem from learners receiving additional relevant 326 information or content. However, in their review, Hew and Cheung (2013) reported that positive effects are not attributable to the podcast per se but how podcasts are used. For example, when podcasts provided additional support to 'classroom' only instruction 
329 improvements were noted - when groups received the same information none or trivial 330 improvements were reported. All of the research reports on tutor created material - no research 331 has considered the impact of learners developing their own original material, but this is posited 332 as having potential for developing learner ownership and deeper engagement (Hew \& Cheung, 333 2013). No empirical findings support this and it is therefore an area for further exploration.

Wiki

335 Research examining the use of wikis is underdeveloped with relatively few studies being 336 undertaken. Those conducted in education have reported mixed results - with improvements 337 assigned to pedagogical design rather than the use of technology in itself (Hew \& Cheung, 338 2013). Poor research design (e.g. lack of pre-tests, single groups) and confounding variables 339 such as different tutors involved with courses and increased staff-student ratios compared with 340 courses not using wikis have also been identified as issues in terms of the impact on learning. 341 In a sport related study, Hastie et al. (2010) implemented wiki technology with two classes of 342 secondary school physical education pupils to design a new invasion game. Data were collected 343 using a reflective $\log$ and interviews. The authors reported use of the technology 344 asynchronously (24/7 classroom) and an extended learning community beyond the classroom.

345 The authors make the case for a 'higher quality learning experience' suggested by increased 346 engagement provided by the technology and student ownership of the task.

347 Blogs

348 In a similar vein to the coaching literature, gains in learning have been reported through using 349 blogs in the wider educational context, particularly linked to learner writing, peer-to-peer 350 learning/ peer interaction, and critical thinking - these conclusions however have to be treated 351 tentatively because of research designs based on single cases and a lack of pre-intervention data (cf. Hew \& Cheung, 2013). Hence it is not always clear if learning gains can be attributed

354 Olofsson, Lindberg and Huage (2013) observed that it was difficult to assess the impact of 355 blogs as a singular approach when it was part of podcasted lectures, course readings and other 356 learning resources. Furthermore, Fakude (2014) observed that in implementing blogs as a 357 reflective and collaborative tool with student nurses, while initially useful as a platform for 358 sharing reflections, not all participants were comfortable using the technology and its use was 359 impaired by limited engagement. 
361 Social media have been used for a range of activities, these include discussions and question 362 and answer, sharing materials, providing support, and organising groups. In their review Hew 363 and Cheung (2013) suggest social media can assist in developing conversations between 364 educators and learners and between learners. So far, no research has been able to link changes 365 in learners or learning to the use of social media specifically as opposed to the increased engagement with tutors through, for example course design. In a sport related study, Goodyear,

367 Casey and Kirk (2014a) looked at the interactions between five physical educators and a 368 facilitator over a two-year period. The authors investigated social media as a means for a 369 facilitator to support multiple teachers in a virtual location overcoming issues of time and cost.

370 The researchers used social media to support in-school activity, and the authors claim this use 371 became a form of inter- and intra-professional reinforcement leading to the development of 372 professional learning and supporting pedagogical change. As with the wider literature, the 373 research design means that causality is difficult to establish, that is, not the technology alone 374 but the level of support could be responsible for the positive findings.

\section{$375 V L E / M O O C$}

376 Massive, open online courses is positioned in the wider educational field as difficult to tell if 377 they "constitute a revolution in higher education or just a fad" (Steffens, 2015, p. 52). 378 Kartensi's (2013) review considered 100 studies on the use of MOOCs and found that the 379 advantages of MOOCs are associated with traditional distance learning (e.g. increased accessibility of course material, asynchronous access, access materials multiple times, selfpaced), that success rates among MOOC participants is in general low, assessment and links to certification are problematic, and it is difficult to ensure learning support, requiring learners to

383 be highly autonomous. Flavin (2016) suggests that MOOCs are most suitable for those with a 384 grounding in the subject with up to $85 \%$ of participants already having a degree - while 385 specifically targeted MOOCs compromises the openness aspect of MOOCs. Democratising access to resources is not the same as access to education (Flavin, 2016). The MOOCs may be useful to support CPD where the outcome of learning adds value to existing professional practice - thus limiting the openness to organisational contexts. 
390 Papasterigiou \& Gerodimos (2013) used a web-based multimedia course to teach PE teachers 391 to teach basketball. A blended learning approach using the web-based course in combination with face-to-face instruction was significantly more effective than conventional face-to-face alone. Russell et al. (2014) implemented a blended online 'physical activity and wellness' course to replace a previously delivered 'face-to-face' programme. The authors reported positive effects associated with distance learning, that is increased accessibility of course material and asynchronous access, students able to access materials multiple times and for students to be self-paced through the programme. Szabo \& Schwartz (2011) blended on-line discussion forums into a 'traditional' face-to-face delivery and reported that this developed learner's critical thinking skills and improved the quality of written reflections. The authors suggesting that on-line tasks need to be purposeful and connected - intervention from the instructor is required, modelling comments, asking higher order questions and prompting learners to sharer reflections and experiences.

Kori et al. (2014) reviewed thirty-three articles that considered blended technology supporting reflection in teachers described as 'technology-enhanced learning'. The authors considered 'technical tools', some kind of instrument that supported reflection, with the tools identified as video, blogs and e-portfolios. Video was used to situate learning, develop habits of reflection and develop self-awareness - which aligns with the reported work in coaching. For example, Walters et al. (2015) used a qualitative case study to examine how a learner409 generated video assessment developed critical thinking and engagement with theoretical concepts, interview data along with improved grades suggested this was the case. However, 411 the authors pointed out importantly that the alignment of learning strategies and assessment 412 methods were the drivers for learning 'transformation' rather than the technology alone. In a 413 different sport related study, Goodyear, Casey and Kirk (2014b) used a co-operative learning 414 model with video to teach an eight-lesson basketball unit to adolescent girls 'disengaged' from 415 physical education. The findings suggested that the use of technology supported the learning 416 design and an opportunity for participants not to engage in the physical aspect of learning the 417 sport - the authors suggesting that partial engagement has the potential to provide a gateway 418 to full participation. Similarly, Casey and Jones (2011) used video for eight weeks with a class 419 of year seven mixed gender students identified as 'disengaged/underachieving'. The video was 420 used with the primary purpose of increasing engagement. The authors reported that the use of 
421 video provided a support to the learning environment and a support for discussion and 422 engagement with disaffected students.

Kori et al.'s (2014) review showed that added predefined guidance and tutor interaction

424 increases effectiveness of the use of technology. The authors identified prompts, guiding 425 questions, and predefined guidance as giving structure and setting limits to learning - while 426 giving depth to critical thinking, helping cement new knowledge and support learning 427 activities. Human interaction took the form of interaction with peers, tutors or mentors. 428 However, most of the research evidence supporting this approach - as with the coaching 429 research - is derived from self-report or participant perceptions. Research that has compared, 430 for example, online blogging with peer comments to traditional essay writing with small group 431 discussion has found no significant difference in student learning. Therefore, technical support 432 alone may not be effective in supporting learning and predefined guidance and human 433 interaction is needed. However, such was the variability of findings there is no conclusion 434 about what type of support works best (Kori et al., 2014). As Lu and Churchill (2014) pointed 435 out, increased social interaction afforded by a social networking environment can be short 436 lived, individual-centred and casual. These authors state that for enhancement to take place 437 there is a need to prescribe learning tasks that show examples of good practice, including 438 authentic tasks, and rewarding good efforts. The authors also argue that a blended approach 439 through multi-channel social interactions support diverse media preferences. The results 440 reported in the literature further highlights the need to consider the wider pedagogical scaffold 441 in which technology fulfils an integral function; that is the interaction between the learner, the 442 learning environment and the intended learning outcomes and the potential role of technology 443 in facilitating these. In addition, while some empirical data are presented some research only 444 presents argumentative discussions that lack empirical support or evidence.

\section{Discussion}

446 This review of literature has identified a number of issues that warrant closer scrutiny. 447 Specifically, these relate to methodological, conceptual and practical issues related to TEL in 448 coaching. The review demonstrates clearly that "educational technology is not a homogenous 449 'intervention' but a broad variety of modalities, tools and strategies for learning” (Ross, 450 Morrison \& Lowther, 2010, p. 19) that is often used in a 'mixed' or 'blended' fashion. 451 Therefore, this next section of the review considers the ways in which TEL is conceptualised, 
452 different forms of evidence used to substantiate claims about TEL, and practical issues related 453 to implementing TEL in coaching.

\section{Methodological Issues}

455 The lack of a structured research agenda and longitudinal methodologies means that there 456 remains a scarcity of published work in coaching that links evidence of the application of 457 technologies to enhancements in learning. As a result, observed outcomes can be attributed to 458 a 'novelty effect' where participants react positively to any new intervention regardless of its merit (cf. Hew \& Cheung, 2013), an issue identified in research in sport (Casey, Goodyear \& 460 Armour, 2016). The question of how 'improvement' is measured and defined also remains, 461 with authors commonly identifying deeper and critical thinking and peer interaction as 462 outcomes equated with learning (e.g. Mendenhall \& Johnson 2010; Lu \& Churchill, 2014), an 463 approach similarly reported in the coaching literature. Indeed, very few studies in the sport, coaching or wider educational literature attempted to explain changes in learning as a result of a TEL intervention, with much of the focus on improving peer-to-peer and tutor interaction and learner 'engagement' and 'learning' assumed to be a by-product or proxy of these outcomes. The absence of empirical research that tracks learning through sustained exposure to TEL environments is clear and provides stimulus for further research.

As a result, research designs are often reflective of a deterministic expectation that technology by itself will bring about changes in learning and practice (cf. Kirkwood \& Price, 471 2014). Across the coaching literature (and the wider educational field) much literature has been 472 essentially descriptive and promotive (Hastie et al., 2010) with most articles simply reporting 473 the utility of using technology, with examples of contexts and suggestions for use. Increased 474 flexibility for learners supports operational goals and does not inform about learning, but can 475 be taken as a proxy for learning by participants (Kirkwood \& Price, 2013). The relatively 476 modest body of work in coaching attempted to highlight how technology was used, what 477 activities were most valuable, and what advantages/disadvantages the technology presented for 478 the learners' experience, or attitudes toward a particular technology. While useful, these 479 outcomes do not demonstrate that technology has enhanced or contributed to 'learning' as the 480 studies typically rely on self-reports of perceptions and attitudes by tutors and students.

481 Determining perceptions can provide useful information in terms of the value and interest of technology in the design, implementation or operational improvement of pedagogical 
environments. However, when considering participant 'learning' the research has so far failed to demonstrate evidence of participants' changes in knowledge as a result of technology integration. The underlying assumption in much of the research is that expressions of attitudes can be equated with learner enhancement - however on a closer inspection it is "inappropriate to conflate attitudes with learner development" (Kirkwood \& Price, 2013, p. 542) - making judgements about effectiveness difficult.

A common research approach in education involves comparing the outcomes from teaching one group using technology with those of a non-intervention group or 'control' who are taught with more conventional means such as classroom instruction (Kirkwood \& Price, 2013). However, the coaching literature often relies on 'single group' research designs, where reported changes in learning are not necessarily due to the manipulation of the technology, hence increasing the difficulty of attributing changes to the intervention. True experimental comparisons however, are not easily achievable in coach education settings and results in quasi-experimental approaches being adopted where the pedagogy is not just technologicallyenhanced but the nature of the intervention supplements or changes the mode of teaching.

498 Causality is then difficult to attribute if variables are not held constant - when additional or 499 supplementary resources or tools are provided any enhancement observed might simply be attributable to the additional inputs or time spent on task rather than the technology being the mediating factor (Kirkwood \& Price, 2014). Moreover, learning has a temporal nature, in that deeper or richer understanding, for example, may not present itself until sometime after the intervention. Therefore, perspectives regarding evidence are not just methodological. They also encompass different views about learning, where this may be characterised as qualitative changes in development relative to the individual, or quantitatively in terms of "exit

506 behaviours' that are the same for everyone. Therefore, concepts of evidence are linked to 507 fundamental beliefs about coaching and learning and what constitutes evidence (Price \& 508 Kirkwood, 2014).

\section{Conceptual Issues}

510 Casey et al. (2016) suggest that few educators are able to incorporate technology into the 511 pedagogical context in purposeful ways, which means that in coaching, technology mediated 512 teaching and/or learning is not a mainstream practice. Part of the problem is the lack of clarity 513 around what is meant by 'technology' and is often taken to focus on the role of technology as 514 a supportive mechanism for already-existing educational activities (Bayne, 2015; Flavin, 
515 2016). As Bayne (2015) suggests, technological variety and multiplicity are 'black-boxed' and 516 separated from the social context and not understood as social objects - and the underlying 517 assumptions are simplistic and 'common-sense'. The assumption in much of the existing 518 literature is that technology can enhance pre-existing objectives (a perspective characterised 519 by instrumentalism), and learning can be transformed by the immanent pedagogical value of 520 technology simply by using them. There is, therefore, an inherent conservatism in the discourse 521 where enhancement assumes the efficacy of the pre-existing pedagogical practices which are 522 not in need of radical shift or displacement but can simply be made better by the application of 523 technology (Bayne, 2015) - there is a danger in coaching that technology could be used as a 524 substitute for poor coach education practice - that is, 'doing things better, rather than doing 525 better things' (cf. Kirkwood \& Price, 2014). Rather than reconstruct educational programmes, 526 the assumption is improvement and consolidation via the utilisation of technology (Bayne, 527 2015). This means that applying technology uncritically within established pedagogical models 528 is problematic because the technology gets manipulated to suit existing pedagogy and is 529 subsumed within an existing pedagogical model (Flavin, 2016). Therefore, there is a gap 530 between the features of technology and the use of technology - with the technology offering a more efficient method but is ultimately static in developing learning as existing pedagogies are relocated to the technology.

Another conceptual issue with the use of technology to enhance coach learning is the difficulty with generalising findings across contexts. Thus, while interventions often focus on the specific application of a technology, details of the teaching and learning interactions, and 536 the social context in which it is situated, are required to understand the context of 537 implementation. In addition, the term 'enhanced', while widely used, is frequently used in an 538 unconsidered and unreflective way with its meaning taken for granted. Therefore, there is a 539 need to avoid the tendency to 'glorify' the capacity of technology to impact learning, 540 conceiving technology as a 'super tool' (Casey et al., 2016; Price \& Kirkwood, 2014).

541 Moreover, the impact on learning will be dependent on how learning is conceived and 542 understood. Decisions about when to use technology, what technology to use and for what 543 purposes cannot be separated from theories and research on learning, instruction, and 544 assessment (Lawless \& Pelligrino, 2007). Technology is only as good as "the pedagogical 545 methods it employs" (Ferster, 2014, p.176).

\section{Practical Issues}


547 Although most TEL applied to coaching projects are relatively small-scale and context-

548 specific, the cumulative lessons learned can provide a useful indication of the benefits of 549 integrating technological tools and resources into coach education and development contexts.

550 From the review, practical benefits of TEL were identified as a means of supporting 551 collaborative learning and peer-support across large cohorts, as technology can enhance 552 communication, knowledge and resource sharing, and engagement in learning environments. 553 Indeed, the addition of technology provides opportunities for flexible, diverse and interactive 554 approaches to assessment, and can be conceptualised as 'learner-centred' in that learners can 555 self-regulate the management of learning activities through asynchronous and flexible access 556 to learning materials (Keppell, Suddaby \& Hard, 2015; Lu \& Churchill, 2014).

However, it must be noted also that technology integration can present a number of practical and logistical challenges. Casey et al. (2016) argue that while there is a generation of active users and consumers of technology, some educators are resistant and struggle to integrate technology in pedagogically sound or innovative ways. For example, there are specific costs to using technology: site licence, administration, technical support, hardware, technology infrastructure, course development, tutor and learner training. The time and effort to overcome possible resistance to new technology and procedures is also a cost factor (Flavin, 2016). In addition, there is limited research to support the notion of a 'digital native' with the picture more nuanced depending on confidence and whether a passive or active user of technologies use of technology in learning when not specifically structured is logistical rather than participatory (Flavin, 2016). Research evidence also suggests learners, while enthusiastic users of some technologies (e.g. social media), would not be in favour of these as a teaching tool suggesting learners practice demarcation in the use of technology (Bayne, 2016).

\section{Conclusions}

571 Technology-enhanced learning environments afford opportunities to expand our existing 572 models of coach development, but, do not impose the explicit conditions for learning (cf. 573 Hannafin \& Land, 1997). Technology can be used to compliment traditional learning 574 environments by providing parallel synchronous and asynchronous learning spaces (de Andres 575 Martinez, 2012). Importantly, effects on 'learning' are not necessarily related to the 576 technologies themselves but how the technologies are used, as "technologies are not a silver 577 bullet and will not independently or autonomously improve learning performance" (Hew \& 578 Cheung, 2013, p.58). Thus, when considering the use of technology in coach education, 
579 pedagogical and instructional strategies need to be developed alongside technologies as 580 pedagogical design is the major factor impacting learning in a TEL environment, including 581 how both tutors and learners are required to adjust to TEL environments compared to traditional 'classroom delivery’ (Hsu et al., 2012).

583 In technology-enhanced learning environments, the processes associated with 584 understanding and the contexts in which it occurs are linked. They emphasize not only 585 assimilation but the development of meta-knowledge for both solving existing problems and 586 generating new ones. Through experience, learners become increasingly facile with available 587 tools and resources, and skilled in assessing how and when to employ them (Hannafin \& Land, 588 1997). An effective learning environment encourages learners to use its resources and tools to 589 derive problems, vary solutions, and "expand the boundaries of their understanding" (Hannafin 590 \& Land, 1997, p. 187), the review suggests that there needs to be a clear alignment in the 591 pedagogical environment between the learners, the learning outcomes and the modes of 592 technological transmission utilised to achieve these. Technology-enhanced environments often 593 provide the conceptual scaffolding and means (e.g. platforms, resources and tools) to promote 594 personal and individual reflection. In this sense technology should be thought of as an enabling 595 tool to promote learning (Hannafin \& Land, 1997). However, facilitating coach learning 596 remains a complicated practice that requires the interweaving of many kinds of specialised 597 knowledge. In their application to coach development, TEL can potentially provide interactive 598 environments that enable individuals to address unique learning interests and needs, study 599 multiple levels of complexity, and deepen understanding (Hannafin \& Land, 1997). 600 Furthermore, it is suggested that the use of TEL establishes the conditions that "enrich thinking 601 and learning, and use technology to enable flexible methods through which the processes can 602 be supported" (Hannafin \& Land, 1997, p. 168). However, the evidence base that supports this 603 in coaching is currently fragmented and weak. Consequently, apart from isolated studies, 604 comparatively little understanding of the role, function and impact of technology in the design 605 of coaching specific learning environments has evolved. 
608

609

610

611

612

613

614

615

616

617

618

619

620

621

622

623

624

625

626

627

628

629

630

631

632

633

634

635

636

637

638

639

640

641

642

Bayne, S. (2015). What's the matter with 'technology-enhanced learning'? Learning, Media and Technology, 40 (1), 5-20.

Casey, A. \& Jones, B. (2011). Using digital technology to enhance student engagement in physical education. Asia-Pacific Journal of Health, Sport and Physical Education, 2 (2), 51-66.

Casey, A. \& Jones, B. (2011). Using digital technology to enhance student engagement in physical education. Asia-Pacific Journal of Health, Sport and Physical Education, 2 (2), 51-66.

Casey, A., Goodyear, V.A. \& Armour, K.M. (2016). Rethinking the relationship between pedagogy, technology and learning in health and physical education. Sport, Education and Society, 22(2), 288-304.

Cushion, C. J., Armour, K. M., \& Jones, R.L. (2003) Coach Education and Continuing Professional Development: Experience and Learning to Coach. Quest, 55, 215-230.

Cushion, C.J. Nelson, L. Armour, K. Lyle, J. Jones R.L., Sandford, R., and O'Callaghan, C. (2010) Coach Learning and Development: A Review of Literature. (Leeds, Sports Coach UK).

de Andres Martinez, C. (2012). Developing metacognition at a distance: sharing students' learning strategies on a reflective blog. Computer Assisted Language Learning, 25 (2), $199-212$.

Douglas, K. \& Carless, D. (2008). Using Stories in Coach Education. International Journal of Sports Science \& Coaching, 3(1), 33-49.

Driska, A.P., \& Gould, D.R. (2014). Evaluating a Problem-Based Group Learning Strategy for Online, Graduate-Level Coach Education. Kinesiology Review, 3, 227-234.

Eraut, M. (1994) Developing Professional Knowledge and Competence. London: Falmer Press.

Erickson, K., Bruner, M.W., MacDonald, D.J., Côté, J. (2008). Gaining Insight into Actual and Preferred Sources of Coaching Knowledge. International Journal of Sports Science \& Coaching, 3(4), $527-538$.

Fakude, L.P. (2014). Blogging to enhance reflective and collaborative learning. African Journal for Physical, Health Education, Recreation and Dance, 1 (1), 61-68.

Ferster, B. (2014). Teaching machines: Learning from the intersection of education and technology. Johns Hopkins University Press: ML, USA

Flavin, M. (2016). Technology-enhanced learning and higher education. Oxford Review of Economic Policy, 32 (4), 632-645.

Gilbert, W., \& Trudel, P. (1999). An evaluation strategy for coach education programs. Journal of Sport Behavior, 22(2), 234-250. 
643 Gilbert, W., \& Trudel, P. (2001). Learning to coach through experience: Reflection in model 644 youth sport coaches. Journal of Teaching in Physical Education, 21, 16-34.

645 Glang, A., Koester, M.C., Beaver, S., Clay, J. \& McLaughlin, K. (2010). Online training in

646

647

648

649

650

651

652

653

654

655

656

657

658

659

660

661

662

663

664

665

666

667

668

669

670

671

672

673

674

675

676

677

678

679

680 sports concussion for youth sports coaches. International Journal of Sports Science \& Coaching, 5 (2), 1-11.

Goodyear, V.A., Casey, a. \& Kirk, D. (2014a). Tweet me, message me, like me: using social media to facilitate pedagogical change within an emerging community of practice. Sport, Education and Society, 19 (7), 927-943.

Goodyear, V.A., Casey, a. \& Kirk, D. (2014b). Hiding behind the camera: social learning within the Cooperative Learning Model to engage girls in physical education. Sport, Education and Society, 19 (6), 712-734.

Grant, A. M., Franklin, J., \& Langford, P. (2002). The self-reflection and insight scale: A new measure of private self-consciousness. Social Behavior and Personality, 30(8), 821836.

Gunawardena, C.N., Hermans, M.B., Sanchez, D., Richmond, C., Bohley, M., \& Tuttle, R. (2009). A theoretical framework for building online communities of practice with social networking tools. Educational Media International, 46(1), 3-16.

Hannafin, M.J. \& Land, S.M. (1997). The foundations and assumptions of technologyenhanced student-centred learning environments. Instructional Science, 25, 167-202.

Hastie, P.A., Casey, A. \& Tarter, A-M. (2010). A case study of wikis and student-designed games in physical education. Technology, Pedagogy and Education, 19 (1), 79-91.

Hay, P., Dickens, S., Crudgington, B. \& Engstrom, C. (2012). Exploring the potential of assessment efficacy in sports coaching. International Journal of Sports Science \& Coaching, 7 (2), 187-198.

Hew, K.F. \& Cheung, W.S. (2013). Use of Web 2.0 technologies in K-12 and higher education: the search for evidence-based practice. Educational Research Review, 9, 47-64.

Hsu, Y.-C., Ho, H. N. J., Tsai, C.-C., Hwang, G.-J., Chu, H.-C., Wang, C.-Y., \& Chen, N.-S. (2012). Research Trends in Technology-based Learning from 2000 to 2009: A content Analysis of Publications in Selected Journals. Educational Technology \& Society, 15 (2), 354-370.

Jarvis, P. (2004) Adult education and lifelong learning: Theory and practice 3rd edition (London, Routledge).

Jones, R. L., Fonseca, J., De Martin Silva, L., Davies, G., Morgan, K. \& Mesquita, I. (2015). The promise and problems of video diaries: building on current research. Qualitative Research in Sport, Exercise and Health, 7 (3). 395-410.

Jones, R.L. \& Turner, P. (2006). Teaching coaches to coach holistically: can Problem-Based Learning (PBL) help? Physical Education and Sport Pedagogy, 11(2), 181-202. 
Jones, R.L., Morgan, K. \& Harris, K. (2012). Developing coaching pedagogy: seeking a better integration of theory and practice. Sport, Education and Society, 17(3), 313-329.

Kartensi, T. (2013). The MOOC. What the research says. International Journal of Technologies in Higher Education, 10, pp. 23-37.

Keppell, M., Suddaby, G. \& Hard, N. (2015). Assuring best practice in technology-enhanced learning environments. Research in Learning Technology, 23, 1-13.

Kirkwood, A. \& Price, L. (2014). Technology-enhanced learning and teaching in higher education: what is 'enhanced' and how do we know? A critical literature review. Learning, Media and Technology, 39 (1), 6-36.

Kori, K., Pedaste, M., Leijen, A. \& Maeots, M. (2014). Supporting reflection in technologyenhanced learning. Educational Research Review, 11, 45-55.

Kuklick, C.R., Gearity, B.T. \& Thompson, M. (2015). The Efficacy of Reflective Practice and Coach Education on Intrapersonal Knowledge in the Higher Education Setting. International Journal of Coaching Science. .9 (2), 23-42.

Kuklick, C.R., Gearity, B.T., Thompson, M. \& Neelis, L. (2016). A case study of one high performance baseball coach's experiences within a learning community. Qualitative Research in Sport, Exercise and Health, 8 (1), 61-78.

Lawless, K.A. \& Pellegrino, J.W. (2007). Professional development in integrating technology into teaching and learning: knowns, unknowns, and ways to pursue better questions and answers. Review of Educational Research, 77 (4), 575-614.

Lu, J. \& Churchill, D. (2014). The effect of social interaction on learning engagement in a social networking environment. Interactive Learning Environments, 22 (4), 401-417.

Mallett, C., Trudel, P., Lyle, J. \& Rynne, S.B. (2009). Formal vs. informal coach education. International Journal of Sports Science and Coaching, 4(3), 325-334.

Mead, S., Spencer, K. \& Kidman, L. (2016). Video self-reflection and coach development in New Zealand. Asia-Pacific Journal of Health, Sport and Physical Education, 7 (2), 139-156.

Mendenhall, A. \& Johnson, T.E. (2010). Fostering the development of critical thinking skills, and reading comprehension of undergraduates using a Web 2.0 tool coupled with a learning system. Interactive Learning Environments, 18 (3), 263-276.

Morgan, K., Jones, R.L., Gilbourne, D., \& Llewellyn, D. (2013). Changing the face of coach education: using ethno-drama to depict lived realities. Physical Education and Sport Pedagogy, 18(5), 520-533.

Olofsson, A.D., Lindberg, J.O. \& Huage, T.E. (2011). Blogs and the design of reflective peerto-peer technology-enhanced learning and formative assessment. Campus-wide Information Systems, 28 (3), 183-194. 
Papastergiou, M. \& Gerodimos, V. (2013). Can learning of basketball be enhanced through a web-based multimedia course? An experimental study. Education and Information Technologies, 18, 459-478.

Partington, M., Cushion, C.J., Cope, E. \& Harvey, S. (2015). The impact of video feedback on professional youth football coaches' reflection and practice behaviour: a longitudinal investigation of behaviour change. Reflective Practice, 16, (5), 700-716.

Piggott, D. (2011). Coaches' experiences of formal coach education: a critical sociological investigation. Sport, Education and Society, 17(4), 535-54.

Price, L \& Kirkwood, A. (2014) Using technology for teaching and learning in higher education: a critical review of the role of evidence in informing. Higher Education Research \& Development, 33 (3), 549-564.

Ross, S.M., Morrison, G.R. \& Lowther, D.L. (2010). Educational technology research past and present; balancing rigor and relevance to impact school learning. Contemporary Educational Technology, 1 (1), 17-35.

Russell, J., Wadsworth, D., Hastie, P. \& Rudisill, M. (2014). Incorporating e-learning to enhance instruction and student experiences in collegiate physical activity courses. Kinesiology Review, 3, 247-252.

Steffens, K. (2015). Competences, learning theories and MOOCS: recent developments in lifelong learning. European Journal of Education, 50 (1), 41-59.

Stodter, A. \& Cushion, C.J. (2014) Coaches' learning and education: a case study of culture in conflict. Sports Coaching Review, 2(1), 63-79.

Stodter, A. \& Cushion, C.J. (2017). What works in coach learning, how, and for whom? A grounded process of soccer coaches' professional learning. Qualitative Research in Sport, Exercise and Health, 9(3), 321-338.

Stoszkowski, J. \& Collins, D. (2014b). Blogs: A tool to facilitate reflection and community of practice in sports coaching? International Sport Coaching Journal, 1 (3), 139-151.

Stoszkowski, J. \& Collins, D. (2015). Using shared online blogs to structure and support informal coach learning- part 1: a tool to promote reflection and communities of practice. Sport, Education and Society, 22 (2), 247-270.

Stoszkowski, J. \& Collins, D. (2016). Sources, topics and use of knowledge by coaches. Journal of Sports Sciences, 34 (4), 794-802.

Stoszkowski, J., \& Collins, D. (2014a). Communities of practice, social learning and networks: Exploiting the social side of coach development. Sport, Education and Society, 19(6), 773-788.

Stoszkowski, J., Collins, D., \& Olsson, C. (2015). Using shared online blogs to structure and support informal coach learning- part 2: The participants' view and implications for coach education. Sport, Education and Society, 1-19, DOI: $10.1080 / 13573322.2015 .1030382$ 
Szabo, Z. \& Schwartz, J. (2011). Learning methods for teacher education: the use of online discussions to improve critical thinking. Technology, Pedagogy and Education, 20 (1), 79-94.

758

759

760

761

762

763

764

765

766

767

768

769

770

771

772

773

774

775

776

777

778
Taylor, S.L., Werthner, P., Culver, D., \& Callary, B. (2015). The importance of reflection for coaches in parasport. Reflective Practice: International and Multidisciplinary Perspectives, 16(2), 269-84.

Townsend, R.C., Cushion, C.J. \& Smith, B. (2017). A social relational analysis of an impairment specific mode of coach education. Qualitative Research in Sport, Exercise and Health. 1-16.

Trudel, P., D. Culver, and P. Werthner. (2013). "Looking at Coach Development from the Coach Learner's Perspective: Considerations for Administrators." In P. Potrac, W. Gilbert, \& J. Denison (Eds.). Handbook of Sports Coaching, pp. 375-387. London: Routledge.

Walters, S. R., Hallas, J., Phelps, S. \& Ikeda, E. (2015). Enhancing the ability of students to engage with theoretical concepts through the creation of learner-generated video assessment. Sport Management Education Journal, 9, 102-122.

Williams, S., Alder, D., \& Bush, A. (2015). A little less conversation; a little more (relational) action please. A fictional dialogue of integrating theory into coaching practice. Sports Coaching Review, 4(2), 115-138.

Wright, T., Trudel, P. \& Culver, D. (2007). Learning how to coach: the different learning situations reported by youth ice hockey coaches. Physical Education and Sport Pedagogy, 12(2), 127-144. 